\title{
Corazonin and locust phase polyphenism
}

\author{
Seiji TANAKA* \\ Laboratory of Insect Life Cycles and Physiology, NIAS at Ohwashi, Tsukuba 305-8634, Japan
}

(Received 11 November 2005; Accepted 26 January 2006)

\begin{abstract}
Phase polyphenism is an adaptive phenomenon in which some traits vary continuously in response to population densities. In locusts, two extreme phases, solitarious and gregarious, that occur at a low and a high density, respectively, are known and intermediate forms called transient phase also occur in a transition between the two phases or at an intermediate density. Establishment of an albino strain of Locusta migratoria led to the discovery of a neuropeptide, corazonin that is involved in the control of the expression of some phase-related traits in this and another locust, Schistocerca gregaria. This paper describes a summary of phase polyphenism research with a particular emphasis on recent studies about the roles of corazonin in locusts. In L. migratoria, injection of the neuropeptide causes albino nymphs to express various body colors often observed in not only solitarious but also gregarious forms irrespective of the rearing density. Both juvenile hormone and corazonin are necessary to express the green solitarious form normally observed in the field. It has also been suggested that this neuropeptide may be involved in the control of phase-related morphometric ratios of $F / C$ and $E / F$ ( $F=$ hind femur length; $C=$ maximum head width; $E=$ elytron length) as well as the development of antennal olfactory sensilla in the two locusts: injection of the peptide mimics crowding effects, thus inducing gregarious characteristics in solitarious (isolated-reared) locusts. Corazonin and related compounds are widespread among insects. Transplantation of the brain and corpora cardiaca from various donors to albino locusts indicates the presence of corazonin or corazonin-like substances in all 18 insect orders so far screened except for the Coleoptera.
\end{abstract}

Key words: Corazonin; Locusta migratoria; Schistocerca gregaria; phase polyphenism; body color

\section{INTRODUCTION}

Locusts are potentially the most destructive pest insects in the world. They often form swarms and migrate over long distances. Locust swarms may consist of billions of individuals and cause serious damage to agricultural crops (Chapman, 1976). The outstanding characteristic of locusts is their ability to show density-dependent phase polymorphism, involving graded changes in morphological, physiological and behavioral traits. At low density, nymphs of the migratory locust, Locusta migratoria L., assume various body colors including green, yellow, brown, reddish and black depending on the habitat background color and humidity. Adults are either greenish or brownish in color. Both nymphs and adults show little tendency to aggregate and they are sedentary. At high density, all nymphs look similar with black and orange body coloration. They show a strong tendency to aggregate and move in bands. Adults are dark brown and often undergo long-distant migration in swarms.

Because of the distinct differences in appearance and behavior, the individuals at low density were once designated as L. danica and those at high density as L. migratoria until Uvarov (1921) formulated the phase polymorphism theory. He described that these two species constitute a single species that changes from one phase to another in response to population density and suggested this species be called L. migratoria. This theory was extended to include the desert locust, Schistocerca gregaria Foskål (Uvarov, 1923, 1966). One of the most important characteristics of phase polymorphism is the presence of intermediate forms called transient phase in addition to the two extreme phases, solitarious and gregarious phases occurring at low and high density, respectively. A shift from solitarious to gregarious, or vice versa, does not take place in one generation, but takes several generations

*E-mail: stanaka@affrc.go.jp

DOI: 10.1303/aez.2006.179 
(Uvarov, 1966). Locusts during the transient period or at intermediate densities show intermediate characteristics. Thus, the variation is continuous, the situation being different from other types of polymorphism or polyphenism in which morphologically distinct morphs such as long-winged and short-winged or apterous morphs occur without forming intermediate morphs (Harrison, 1980; Pener, 1985; Dingle, 1996).

Numerous studies have been conducted in relation to phase polymorphism (Uvarov, 1966, 1977; Fuzeau-Braesch, 1985; Dale and Tobe, 1990; Pener, 1991; Pener and Yerushalmi, 1998; Applebaum and Heifetz, 1999) and the phase polymorphism theory has been widely accepted. However, the endocrine mechanism controlling phase polymorphism has not been well understood. Our laboratory started working on this subject 15 years ago and our findings shed some new insights into the physiological mechanisms for the control of phaserelated body color and morphological changes in L. migratoria and S. gregaria. Here, I will briefly review the history of research on this subject and outline our findings including some unpublished data.

Because the term 'polymorphism' is often used for genetically controlled variations, the term 'polyphenism' is more appropriate to describe environmentally induced variations (Dingle, 1996). Therefore, phase polyphenism instead of phase polymorphism will be used in this paper.

\section{PHASE POLYPHENISM}

Phase polyphenism has been recognized in several species of locust (Faure, 1932; Uvarov, 1966, 1977). L. migratoria and S. gregaria are the most intensively studied species, mainly because of their economic importance. Table 1 compares phase-related differences in the former species. Body color is one of the most conspicuous phase-related traits observed in both species. Solitarious nymphs show cryptic body coloration, whereas gregarious nymphs develop black patterns in both species, although the black patterns can be induced relatively quickly by crowding even before the locusts attain the gregarious phase. Differences in adult body shape, often expressed as $F / C$ and $E / F$ ratios ( $F=$ hind femur length; $C=$ maximum head width; $E=$ elytron length), are another important phase-re-
Table 1. Phase related-differences in L. migratoria (for references, see text)

\begin{tabular}{|c|c|c|}
\hline Traits & Solitarious & Gregarious \\
\hline \multicolumn{3}{|l|}{ Morphological } \\
\hline Body color & Green, brown & Black patterns \\
\hline Pronotum & Convex & Concave \\
\hline$F / C$ ratio $^{\text {a }}$ & Large & Small \\
\hline$E / F$ ratio $^{\mathrm{a}}$ & Small & Large \\
\hline No. of antennal sensilla & Large & Small \\
\hline \multicolumn{3}{|l|}{ Behavioral } \\
\hline Aggregation & No & Yes \\
\hline General activity & Low & High \\
\hline Flight capability & Low & High \\
\hline Pre-copulatory behavior & Short & Long \\
\hline Copulation & Short & Long \\
\hline $\mathrm{P}_{2}^{\mathrm{b}}$ & High & Low \\
\hline \multicolumn{3}{|l|}{ Physiological } \\
\hline Nymphal growth & Slow ( 5 or 6 instars) & Rapid (5 instars) \\
\hline Fertility (No. of eggs) & Large & Small \\
\hline (Egg size $)$ & Small & Large \\
\hline
\end{tabular}

${ }^{\mathrm{a}} F$, hind femur length; $C$, maximum head width; $E$, elytron length.

${ }^{b} \mathrm{P}_{2}$ is the proportion of offspring sired by the second male to mate.

lated variation. Gregarious locusts have a lower $F / C$ ratio and a higher $E / F$ ratio than solitarious ones (Dirsh, 1951, 1953). Locusts in the two phases also show differences in shape of the pronotum (Dirsh, 1953) and numbers of sensilla on the antennae (Greenwood and Chapman, 1984; Heifetz et al., 1994; Ochieng et al., 1998).

Locusts display characteristic changes in behavior in response to population density. Solitarious locusts tend to avoid each other, whereas gregarious locusts tend to aggregate. Gregarious nymphs form bands and display a behavior called marching, and adults swarm and often conduct long-distant migration. Their behavior in each phase is not fixed but flexible. For example, solitarious individuals can be induced to behave in a gregarious manner by giving them a chance to experience crowding for $2 \mathrm{~h}$ (Ellis, 1962). Tactile and visual stimuli are involved in the induction and maintenance of gregarious behavior (Ellis, 1962). Interestingly, stimulation of solitarious locusts with fine wires or a crowd of different species induces gregarious behavior. These observations have been confirmed by similar studies (Simpson et al., 2001; Lester et al., 2005). Pheromones play a role in the control of behavior in locusts (Loher, 1990; Byers, 1991; Pener, 
1991; Pener and Yerushalmi, 1998) and their chemical structures and significance were intensively studied in the last decade (Torto et al., 1994, 1996; Ferenz and Seidelmann, 2003; Hassanali et al., 2005).

Recently, it was demonstrated that prolonged pre-copulatory mounting increases the length of copulation, which in turn increases the $\mathrm{P}_{2}$, the proportion of offspring sired by the second male to mate, in L. migratoria showing multiple mating (Zhu and Tanaka, 2002). This phenomenon was confirmed and found to be specific to gregarious (crowd-reared) populations (Tanaka and Zhu, 2003). The $P_{2}$ value, length of pre-copulatory mounting and length of copulation are all different between phases (Table 1), suggesting a phase-specific reproductive strategy in this locust.

\section{THE ROLE OF JUVENILE HORMONE (JH)}

Half a century ago, Joly and Joly (1954) demonstrated that implantation of extra corpora allata (CA) induced a green body color in gregarious (crowd-reared) nymphs of L. migratoria, indicating that $\mathrm{JH}$ produced by the glands is responsible for the induction of green color. This green-color inducing effect was confirmed by many workers using a similar means (e.g. Staal, 1961) and by the administration of synthetic $\mathrm{JH}$ and $\mathrm{JH}$ analogs (e.g. Applebaum et al., 1997). Destruction of the CA in solitarious green nymphs caused the green color to fade away, but failed to develop the black and orange coloration typical for gregarious forms in those individuals, and the involvement of another factor inducing the expression of gregarious body coloration was pointed out by Pener et al. (1992), although the mechanism inducing the gregarious coloration remained unknown.

\section{PIONEER STUDIES ON THE DARK-COLOR INDUCING FACTORS}

Nickerson (1956) suggested a steroid factor in the hemolymph as a dark-color inducing substance in gregarious nymphs of $S$. gregaria. He observed that injection of hemolymph from gregarious nymphs increased the black patterns in solitarious nymphs. Staal (1961) carried out a series of elegant experiments to test the roles of various organs in the control of phase-related traits and found that nymphs of L. migratoria implanted with extra corpora cardiaca (CC) increased the black patterns, whereas surgical removal of CC produced an opposite effect. Ellis and Carlisle (1961) reported that removal of the prothoracic glands from isolatedreared nymphs of $S$. gregaria led to the appearance of black patterns and yellow background color observed in gregarious forms. However, Staal (1961) found that implantation or removal of these glands did not produce such effects in L. migratoria. Girardie and Cazel (1965) observed that the dark body color became lighter when the $\mathrm{C}$ cells of pars intercerebralis were destroyed by microcautery in gregarious nymphs of L. migratoria. Although these studies indicated the presence of dark-color inducing factors in the brain, $\mathrm{CC}$, prothoracic glands and hemolymph in locusts, their chemical identity remained undetermined. Besides the black patterns and green color, locusts develop other dark colors such as yellow, brown, beige, orange, reddish and black (Faure, 1932; Tanaka, 2005). However, no information was available about the hormonal factor(s) responsible for the induction of these colors.

\section{DISCOVERY OF AN ALBINO MUTANT DE- FICIENT IN THE DARK-COLOR INDUCING HORMONE}

Albinism is not a rare phenomenon in animals (Halls, 2004). This is particularly true for locusts in the laboratory (Hunter-Jones, 1957; Pener, 1965; Verdier, 1965). We established an albino strain of L. migratoria by selecting albino mutants that had appeared spontaneously in a laboratory stock originally derived from Okinawa, Japan. The albinism in this strain is controlled by a simple Mendelian unit (Hasegawa and Tanaka, 1994). Locusts of this strain are all whitish in color under crowded conditions, but capable of expressing the green color under isolated conditions, as reported for an albino strain of a European L. migratoria (Verdier, 1965). We discovered that this albino strain lacks a darkcolor inducing factor that is normally present in the brain, $\mathrm{CC}$ and thoracic ganglia of this species: implantation of the organs taken from normal (pigmented) nymphs into albino nymphs caused some of the latter to turn gray, yellow, brown, or black, looking like normal solitarious individuals, and others to develop black and orange coloration like 
that of normal gregarious hoppers (Tanaka, 1993). Using the same technique, a factor inducing dark color in albino L. migratoria was also suggested to be present in the CC of S. gregaria (Tanaka and Yagi, 1997) and another acridid, Gastrimargus marmoratus (Tanaka, 2000c). The partial characterization revealed that the CC factors in L. migratoria and $S$. gregaria were peptidic substances because their dark-color inducing activity was retained after heating, but lost after incubation with a proteinase (Tanaka and Pener, 1994a, b; Tanaka and Yagi, 1997).

\section{IDENTIFICATION OF THE DARK-COLOR INDUCING FACTORS}

We made methanol extracts of CC from normal $L$. migratoria and $S$. gregaria to determine the primary structures of the dark-color inducing neuropeptides using the albino bioassay developed by Tanaka and Pener (1994a). Interestingly, the methanol extracts show a dark-color inducing activity only when mixed with oil for injection, but fail to do so if dissolved in an aquatic solution and injected. Thanks to recent progress in analytical technology, the two neuropeptides extracted from these locusts were determined to be identical to Sca-corazonin (Tawfik et al., 1999) that had been isolated previously from the American grasshopper, Schistocerca americana by Veenstra (1991) without known function (Fig. 1). This grasshopper exhibits so-called green-brown polyphenism and variation in intensity of black patterns in response to environmental factors, particularly temperature (Tanaka, 2004a). Recently, it was demonstrated that corazonin induces black patterns in this grasshopper when injected, but does not affect the background color (Tanaka, 2004b).

Antisera against corazonin were developed to observe the distribution of immunoreactive cells in the central nervous system of locusts. As expected from the results of implantation experiments in a previous study (Tanaka, 1993), we confirmed that strong immunoreactivity was detected in the brain, $\mathrm{CC}$ and thoracic ganglia in normal individuals of L. migratoria but not in albinos (Schoofs et al., 2000, 2001; Baggerman et al., 2001; Roller et al., 2003).

The dark-color inducing factors in the brain and CC suggested by Staal (1961) and Girardie and Cazel (1965) are likely to be corazonin, because nymphs of L. migratoria, deficient in this neuropeptide (i.e. albino mutant) fail to express all the non-green dark colors observed in normal individuals. Nickerson (1956) suggested the presence of a steroid factor with dark-color inducing activity in the hemolymph in $S$. gregaria. Whether or not this hemolymph factor is identical to the CC factor or corazonin has not been demonstrated.

The presence of corazonin or corazonin-like substances in other locusts and related insects was indicated by the albino bioassay (Tanaka, 1993, 2000c): implantation of brain or CC taken from these insects caused darkening in albino locusts. The CC of Gryllus bimaculatus induced black patterns in green solitarious nymphs of normal $S$. gregaria when implanted (Tanaka and Yagi, 1997). We attempted to identify the chemical nature of the factors from G. bimaculatus and Bombyx mori and found another corazonin molecule type, Pea-corazonin (Fig. 1; Hua et al., 2000). This molecule was first isolated from a cockroach, Periplaneta americana, as the most potent cardiostimulatory peptide (Veenstra, 1989). It is as potent as Sca-corazonin in terms of dark-color inducing activity in locusts (Hua et al., 2000), but neither of them is involved in the control of pigmentation in non-locust insects. In B. mori, both types of corazonin reduce silk spinning activity slightly when injected (Tanaka, Y. et al., 2002). Likewise, a third type of corazonin synthesized based on the genomic library of the European honey bee, Apis mellifera (Fig. 1), was recently shown to exert a dark-color inducing effect in albino $L$. migratoria and a suppressing effect on spinning activity in $B$. mori (Roller et al., 2006; Verleyen et al., 2006).

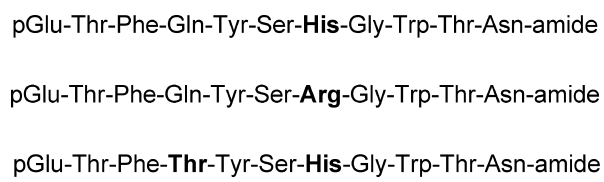

Fig. 1. Corazonin molecule types. Different amino acids are emphasized.

\section{Sca-corazonin \\ Pea-corazonin}

Apm-corazonin 
Thus, three types of corazonin have been identified in insects (Tanaka, 2005).

\section{THE ROLE OF CORAZONIN AND ITS IN- TERACTION WITH JH IN THE CONTROL OF BODY COLOR}

In solitarious nymphs, the body color depends on various environmental factors including humidity, habitat background color and temperature (Pener, 1991). In response to environmental conditions, they change their body color rather quickly, although it may take one or two molts before changes occur. The variety of colors they express and the way they change their body color in response to environmental factors appeared to indicate a complicated hormonal mechanism involving various hormones.

The possibility that a relatively few hormones may explain this body-color polyphenism was indicated by implantation experiments in which $\mathrm{CC}$ taken from a cricket, G. bimaculatus were systematically transplanted into albino locusts (Tanaka, 1996). As mentioned, the CC of this cricket contains Pea-corazonin that can induce darkening in locusts when injected. In response to different timings of CC implantation, the albino recipients expressed various body colors looking similar to those observed not only in solitarious but also gregarious forms (Tanaka, 1996).

Using synthetic Sca-corazonin, the role of this neuropeptide in the control of body color was examined with albino locusts (Tanaka, 2000a). Albino nymphs were variously treated during the third stadium and their body color was observed after ecdysis to the following stadium. The results indicated that albino nymphs injected with the peptide at the beginning of the third stadium turned black completely after the following ecdysis. However, when a low dosage was applied, they developed purple, brown and dark brown colors. Nymphs injected at the end of the third stadium turned reddish without black patterns or spots in the fourth stadium. These body colors were similar to solitarious forms often encountered in the field. Nymphs with black and orange coloration looking like the gregarious body coloration also appeared when injected shortly after the mid stage of the third stadium (Tanaka, 2000a, b). It should be noted that all albino nymphs were kept crowded throughout the experiments. This suggests that albino nymphs may develop various solitarious body colors without experiencing a low density or isolation if they receive appropriate dosages of corazonin at appropriate stages.

Implantation of extra CA, a JH analog (methoprene) and JH III all induced green body color in albino nymphs (Tanaka, 1993; Hasegawa and Tanaka, 1994; Tanaka, 2000b). However, these nymphs failed to develop a brown or reddish color on the ventral surface and legs that was characteristically manifested in normal solitarious green forms of this locust. Such body coloration can be obtained in albino nymphs only when both $\mathrm{JH}$ and corazonin are injected (Tanaka, 2000b). Thus, green solitarious nymphs require both $\mathrm{JH}$ and corazonin to express the characteristic body color. The amount of corazonin present in the CC or brain appears similar between the two phases of a normal strain (Tanaka and Pener, 1994a).

These results appear to suggest that corazonin and $\mathrm{JH}$ can explain the body color polyphenism in L. migratoria. If this is true, one may expect that injection of corazonin would cause normal solitarious nymphs to develop the gregarious coloration without exposing them to crowding, and normal gregarious nymphs to turn even darker. It was demonstrated that such changes in body color actually could occur (Tanaka, 2000a, b).

Figure 2 illustrates a hypothesis to explain the hormonal control of body color polyphenism in $L$. migratoria. Some solitarious nymphs are black or brown in color if they occur in habitats with a black or brown background. Such body colors are induced depending on the corazonin titer at the beginning of the previous stadium. Black individuals would be produced if the titer is high (Fig. 2D), whereas brown ones would be produced if it is low (Fig. 2E). If the peptide titer is very low until shortly before ecdysis, the resulting nymphs would develop reddish color after ecdysis (Fig. 2F). Green solitarious nymphs with brownish color on the legs and the ventral side of the body require both $\mathrm{JH}$ and corazonin in the second half of the previous stadium (Fig. 2C). With $\mathrm{JH}$ alone, the body color turns green without developing the brownish color (Fig. 2B). At high density, gregarious nymphs with black patterns and an orange background color appear. In this case, the JH titers are low and the peptide titers remain low until shortly after the mid stage of the previous stadium 


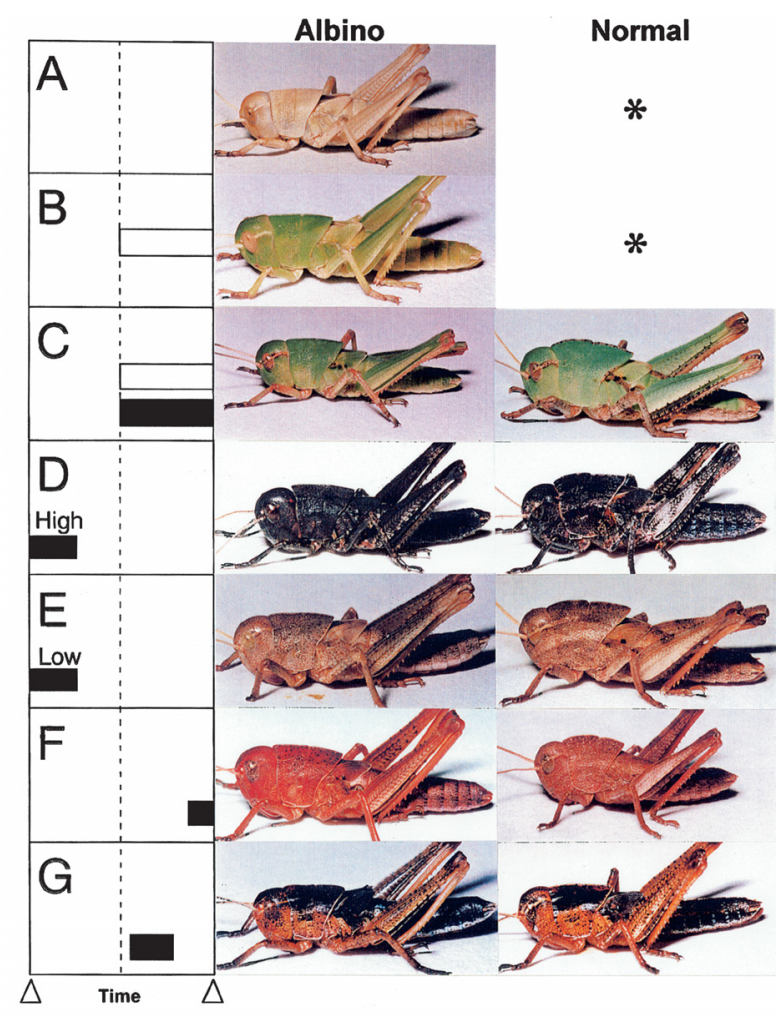

Previous stadium

Fig. 2. A hypothesis explaining the hormonal control of body-color polyphenism in L. migratoria (Tanaka, 2000b). Open squares indicates the presence of juvenile hormone and closed ones that of corazonin. The titers of respective hormones determine the type of body coloration expressed in the following nymphal stadium. For a more detailed explanation, see the text.

(Tanaka, 2000b). For a certain type of body coloration to be maintained in successive nymphal stadia, the specific changes in corazonin and $\mathrm{JH}$ titers required for the expression would be repeated in each stadium.

Temperature influences the expression of body color in locusts. In $S$. gregaria, intensive darkening occurs at low temperature and light-colored individuals appear at high temperature (Husain and Ahmad, 1936). The same phenomenon occurs in L. migratoria in which normal nymphs reared at $42^{\circ} \mathrm{C}$ turn whitish, looking like albino individuals (Tanaka, 2003). It appears that the loss of the dark color at the high temperature is caused by reduced concentrations of corazonin rather than by inactivation of the receptor system of this peptide, because the sensitivity to injected corazonin remained unchanged. Thus, whitish individuals turn darker even at a high temperature if they are injected with the peptide (Tanaka, 2003).

Body color polyphenism looks simpler in $S$. gregaria than L. migratoria. In the former, solitarious nymphs have a green or beige background color, whereas gregarious nymphs develop black patterns with an orange or yellow background color (Faure, 1932). As in L. migratoria, JH is responsible for the induction of the green color in this locust (Roussel and Perron, 1974; Mordue (Luntz), 1977). Implantation of extra CC induced black patterns in green solitarious nymphs (Tanaka and Yagi, 1997). In this case, the background green color was retained, but the compound eyes were strongly pigmented like those of gregarious nymphs. We examined the role of corazonin in this locust by injecting the peptide into green nymphs. Third stadium nymphs thus injected changed the body color after the following ecdysis and they became indistinguishable from gregarious ones of the same (4th) stadium, in spite of the fact that they had been kept in isolation continuously (Tawfik et al., 1999), whereas green nymphs injected at the penultimate (4th) stadium developed black patterns after ecdysis to the last stadium but failed to develop the reddish or yellow background color characteristic of gregarious last stadium nymphs (Tanaka, 2001). Therefore, in the last nymphal stadium, corazonin is responsible for the induction of black patterns only, and another factor seems to be involved in the control of the background color in this locust (Tanaka, 2001), the situation being similar to that for $S$. americana, in which injection of corazonin induces the black patterns but not the red wine background color (Tanaka, 2004b).

Corazonin can induce dark color in other acridid species when injected. All five Japanese species including Acrida cinerea, G. marmoratus, Nomadacris succincta, Oxya yezoensis, Atractomorpha lata (Tanaka, 2000c) and one Israeli species, Oedipoda miniata (Yerushalmi and Pener, 2001), have been demonstrated to turn darker after injection of this peptide. These results might indicate a common function of this peptide in the control of body color in this group of insects. As will be mentioned later, this neuropeptide or related substance(s) has been shown to occur in the brain and CC of those Japanese species (Tanaka, 2000c). 


\section{HORMONAL CONTROL OF OTHER PHASE- RELATED CHARACTERS}

Body dimensions. Probably the most interesting question to be asked next is whether or not corazonin is involved in the control of other phase-related characters. We tested this possibility by injecting the peptide into solitarious locusts. The shape of pronotum is more convex in solitarious (isolated-reared) individuals than in gregarious (crowd-reared) ones. In L. migratoria, injections of corazonin in the second and third stadia caused isolated-reared nymphs to develop a less convex pronotum in the last (5th) nymphal stadium and adult stage compared with that for oil-injected controls (Tanakas, S. et al., 2002). In this case, it is important to separate individuals with different nymphal instars, because individuals with an extra (6th) stadium tend to have more solitarious characteristics than those with five nymphal stadia. It was also demonstrated that injections of corazonin into isolated-reared nymphs caused a shift in morphometric ratios of $F / C$ and $E / F$ at the adult stage towards the values typical for gregarious forms in L. migratoria (Fig. 3; Tanakas, S. et al., 2002) and $S$. gregaria (Hoste et al., 2002b; Breuer et al., 2003). In the latter, a significant effect of the peptide was obtained only in males. However, this conclusion was based on a mixture of individuals with different nymphal stadia. Thus, we re-examined the effect of corazonin in this locust. The results confirmed that the number of nymphal stadia had a significant effect on the adult morphometric ratios and we thus analyzed data by separating individuals with different nymphal stadia (Maeno et al., 2004). As a result, injections of corazonin into isolated-reared nymphs were found to cause a significant shift in $F / C$ and $E / F$ ratios towards the values typical for gregarious adults in both sexes. Furthermore, it was revealed that the earlier the injection during the nymphal stage the larger the 'gregarizing' effects of the peptide on these morphometric ratios in this species as well as L. migratoria (Maeno et al., 2004).

Corazonin influences the morphometric characteristics of L. migratoria. However, the Okinawa albino strain, deficient in this peptide, displays phase-related morphometric changes to some extent (Yerushalmi et al., 2001; Hoste et al., 2002a; Tanaka, S. et al., 2002). This fact suggests that the

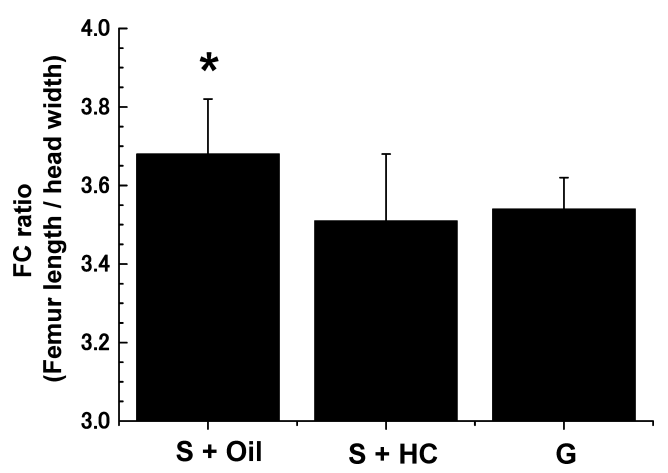

Fig. 3. Effect of corazonin injections on adult $F / C$ ratio in L. migratoria. Solitarious (isolated-reared) adults (S) injected with corazonin during the nymphal stage had significantly reduced $F / C$ ratios compared with oil-injected controls but their values were similar to those for gregarious (crowd-reared) controls. An asterisk indicates a significant difference from each of the other groups (Mann-Whitney $U$-test; $p<0.05$ ) (based on data from Tanaka, S. et al., 2002).

presence or absence of this peptide alone may not explain the whole phenomenon. However, we cannot exclude the possibility that this albino strain has a mutated peptide that does not induce dark color but retains other functions of the intact corazonin. It has been demonstrated that the whole amino acid sequence of corazonin rather than a well-defined active core sequence is necessary for the dark-color inducing activity in albino L. migratoria (Yerushalmi et al., 2002; Tanaka et al., 2003). On the other hand, Nolte $(1967,1968)$ reported that albino locusts do not show gregarious characteristics and constitute an extreme solitarious phase. It is possible that the albinism is caused by different mechanisms in different albino strains.

The role of $\mathrm{JH}$ in the control of phase-related morphometrics has often been argued. Staal (1961) obtained various intermediate morphometric values in adult locusts by implanting extra CA during the nymphal stage. He stated that it is desirable to distinguish, in the resulting adults, between the morphometric changes produced during nymphal development and those resulting from partial inhibition of metamorphosis. By reviewing relevant studies, Pener (1991) concluded that although the greencolor inducing effect of $\mathrm{JH}$ is not doubted, $\mathrm{JH}$ is not a primary factor in the control of phase polyphenism in locusts. Applebaum et al. (1997) applied a $\mathrm{JH}$ analog on crowd-reared nymphs of L. migratoria and S. gregaria and found that the treatment did not induce solitarious morphometric 
ratios in those individuals after adult emergence. In some populations of L. migratoria, green body coloration is observed not only in solitarious individuals but also in gregarious ones. The proportion of greenish adults sampled from a swarm population in Jiminay, Uygur region of China in 2004 was $26.6 \%$ (Tanaka and Zhu, 2005). If high JH concentrations are responsible for the induction of both green coloration and solitarious body shape, one may expect greenish adults to have more solitarious morphometric values than brown adults in such populations. However, no significant difference was observed in morphometric ratios between greenish and brownish adults in a sample taken from the migrant population (Tanaka and Zhu, 2005). In fact, some individuals with a concave pronotum shape and morphometric ratios typical for gregarious forms were greenish in color. These results, based on field-collected individuals, appear to support the notion that JH-inducing green body color is not involved in the control of phase-related morphometric changes.

Antennal sensilla. The locust antennae develop various sensilla. Because pheromones are important factors controlling locust behaviors, the antennal olfactory sensilla are likely to serve a pivotal role in the control of phase polyphenism. Furthermore, Ellis (1962) reported that grouping behavior was considerably reduced if the locusts that had been reared in a crowded environment had the antennae amputated shortly before the observations. In both L. migratoria and S. gregaria, the numbers of antennal sensilla are larger in solitarious locusts than in gregarious ones (Greenwood and Chapman, 1984; Heifetz et al., 1994; Ochieng et al., 1998), although the significance of such differences is not well understood. We explored the possible involvement of corazonin in the control of development of antennal sensilla by injecting the peptide into isolated-reared nymphs of L. migratoria at the second and third stadia (Yamamoto-Kihara et al., 2004). Among the four types of olfactory antennal sensilla, coeloconic, trichoid, basiconic type $\mathrm{A}$ and basiconic type $\mathrm{B}$, the abundance of coeloconic sensilla in the peptide-injected locusts was significantly reduced when compared with the oilinjected counterparts kept in isolation, but similar to that for untreated crowd-reared adults. This result indicated that the injection of corazonin mimicked a crowding effect. We also tested this 'gre-

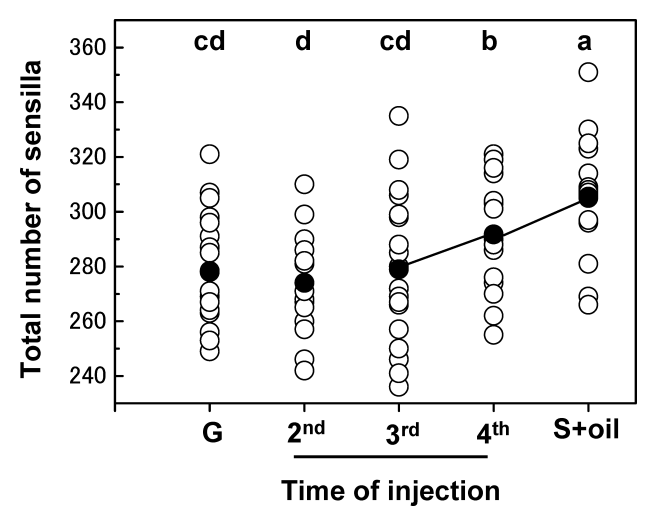

Fig. 4. Effect of corazonin injections on the abundance of olfactory sensilla on the eighth antennal segment of adult females in $S$. gregaria. Corazonin was injected into solitarious (isolated-reared) nymphs at the second, third and fourth nymphal stadia. Controls were injected with oil alone at the third stadium and continuously kept in isolation (S) or un-injected and kept crowded as nymphs $(\mathrm{G})$. Open circles indicate individual datum points and closed circles the mean. Different letters in the figure indicate significant differences at $p<0.05$ by ANCOVA followed by Fisher's PLSD test (Maeno and Tanaka, 2004).

garizing' effect of corazonin on S. gregaria by a similar method (Maeno and Tanaka, 2004). The total number of sensilla was significantly reduced in isolated-reared individuals after injection of the peptide compared with oil-injected controls, and the values became similar to those for crowdreared individuals (Fig. 4). In this locust, corazonin influenced the abundance of all types of olfactory sensilla except for the basiconic type B. It was also found that the effect of corazonin varied with the time of the injection in both $S$. gregaria and L. migratoria; the earlier the injection, the larger the effects on the abundance of total antennal sensilla (Fig. 4), although the way in which the injection affected the abundance varied with the sensillum type (Maeno and Tanaka, 2004).

Hatchling characters. Phase-related differences in body color and behavior have been noticed in the hatchlings of L. migratoria and $S$. gregaria. Dark hatchlings tend to march more than pale hatchlings and this behavior characteristic of gregarious forms lasts at least until the second stadium (Ellis, 1953, 1959). The hatchling body color is influenced by the degree of crowding of the parents as adults. Hunter-Jones (1958) systematically examined this phenomenon and provided conclusive evidence that crowded parents produce dark hatchlings that are relatively heavy, and isolated 
parents produce pale, lighter ones in both L. migratoria and $S$. gregaria. Therefore, the parental density during the adult stage is important in determining the body color and phase-related behavior in the hatchlings of their progeny. These conclusions were recently confirmed for $S$. gregaria by Islam et al. (1994a, b).

Cassier $(1964,1965)$ has shown that the implantation of extra CA into gregarious adults of $L$. $m i$ gratoria produces lighter colored hatchlings, indicating that JH may have some role. Islam (1995) demonstrated that $\mathrm{JH}$ analogs caused gregarious (crowd-reared) adults of $S$. gregaria to produce smaller but more eggs, just like those produced by untreated solitarious (isolated-reared) adults, although none of the eggs treated with the analogs hatched.

A small hydrophilic factor present in the foam plugs of egg pods originating from the accessory glands of crowded female adults was claimed to be responsible for the darkening and gregarious behavior of hatchlings in S. gregaria (McCaffery et al., 1998; Hagele et al., 2000), but the results were not necessarily consistent (p. 359, McCaffery et al., 1998). Furthermore, the dark-color inducing effect of the accessory gland factor was not reproduced by subsequent studies from the same laboratory (Hägele et al., 2000). According to our preliminary observations, eggs collected and isolated before the deposition of a foam plug by the crowded female produced black hatchlings, indicating that the foam plug is not essential for the induction of darkening (Tanaka and Maeno, unpublished data). It is possible that the mechanisms controlling body color and behavior in hatchlings are different, as suggested for L. migratoria by Ellis (1959). More recently, Malual et al. (2001) examined this phenomenon in relation to the behavior of hatchlings in $S$. gregaria and provided experimental evidence to suggest C-8 unsaturated ketones as a gregarizing factor. In this case, hatchlings that were exposed to these compounds did not change their body coloration (Hassanali, A., personal communication). C-8 unsaturated ketones have low solubility in water, and whether this is sufficient to account for the effects observed by the former group in water extracts remains to be established. The chemical structure of the water-soluble factor from the accessory gland should be determined to settle the problems.

The role of corazonin in the control of hatchling coloration has not been tested directly. Preliminary experiments indicated that repeated injections of this peptide into solitarious female adults of $S$. gregaria did not cause their hatchlings to turn darker (Tanaka, 2001). Effects of corazonin injection into eggs or embryos on the hatchling body color have not been tested.

Behavior. Solitarious and gregarious locusts display conspicuous behavioral differences in late stadium nymphs and adults, as mentioned above. Whereas much has been learnt about the regulatory roles of pheromones, particularly aggregation pheromones, in the control of locust behavior (Hassanali et al., 2005), relatively little is understood about the hormonal mechanism. Many studies have reported phase-related differences in $\mathrm{JH}$ and ecdysteroid titers and their functional roles in the control of behaviors such as aggregation behavior and marching activity, but no major role had been demonstrated for either hormone (Dale and Tobe, 1990; Pener, 1991; Applebaum et al., 1997; Pener and Yerushalmi, 1998). However, a recent study by Ignell et al. (2001) revealed that JH does not change the sensitivity of antennal receptor neurons to the aggregation pheromone, but influences that of olfactory interneurons in the antennal lobe of $S$. gregaria.

A possible function of corazonin in behavior has been tested by Hoste et al. (2003) with L. migratoria, but treatment of solitarious nymphs with the peptide did not change their behavior towards gregariousness. However, it is premature to conclude that corazonin is not involved in the control of phase-related behavioral change in locusts because of some unsolved problems. First of all, only one experiment with one dosage has been tested. Second, none of the hormone-injected nymphs tested by Hoste et al. (2003) assumed the gregarious body coloration (i.e. orange and black coloration). Instead, they all turned black after the injections. Such body coloration is often observed among solitarious nymphs (see Fig. 2D). Thus, there is no surprise that Hoste et al. failed to observe a shift in behavior towards gregariousness in the above experiment. However, it is known that behavioral changes can be induced by a short period of isolation or gregarization (e.g. $30 \mathrm{~min}$, Ellis, 1963) that is not sufficient to cause any substantial change in body color. Therefore, phase-related behavioral changes are likely to be controlled by some other 
factor(s) that responds quickly to changes in crowding conditions.

Recently, such candidates were suggested by Rogers et al. (2004), who measured the amounts of amino acids and biogenic amines in the central nervous system in $S$. gregaria under various conditions. A change in rearing density caused rapid changes in some chemicals, but such changes were not sustained under continuously crowded or isolated conditions, indicating that these chemicals cannot be the primary factors sustaining the gregarious behavior. The same researchers also examined long-term changes in those chemicals, but their data are difficult to interpret, because most samples were based on a mixture of individuals at different ages ( 2 to $5 \mathrm{~d}$ ). Such compounds and hormones often undergo substantial fluctuations over a few days or even hours. For example, several-fold differences are observed in concentrations of some biogenic amines in the brain and $\mathrm{CC}$ between 0 and 1-day old, fifth stadium nymphs of L. migratoria (Tanaka and Takeda, 1996). Circadian variations of serotonin contents in the brain and hemolymph of a cricket, Acheta domesticus have been observed (Muszynska-Pytel and Cymborowski, 1978). In another cricket, Gryllus firmus, the hemolymph $\mathrm{JH}$ titer exhibits a large diurnal cycle (Zhao and Zera, 2004). Thus, to obtain meaningful data, samples need to be collected and analyzed by considering those phenomena. Furthermore, it is to be kept in mind that a mere correlation between phase and certain chemicals does not prove any causal relationship, and experimental approaches are necessary to uncover the underlying mechanisms.

\section{CORAZONIN IN OTHER INSECTS}

The albino bioassay has revealed that corazonin molecules or similar compounds are widespread among insects. Table 2 shows a list of groups of insects and related animals so far tested: albino locusts implanted with brains and/or CC taken from other animals developed dark color or remained whitish. Insects belonging to a total of 18 insect orders have been shown to have a dark-color inducing activity when their brain or/and $\mathrm{CC}$ were implanted into albino locusts. These orders contain both pterygote and apterigote species, indicating that corazonin or corazonin-like compound is old
Table 2. A list of insects and related arthropods tested by the albino bioassay for dark-color inducing activity

\begin{tabular}{|c|c|c|c|}
\hline Class & Order & $\begin{array}{l}\text { No. species } \\
\text { tested }^{\text {a }}\end{array}$ & References \\
\hline Arachnida & Araneida & $0 / 2$ & $*$ \\
\hline Crustacea & Isopoda & $0 / 1$ & $*$ \\
\hline \multirow[t]{19}{*}{ Insecta } & Thysanura & $1 / 1$ & Roller et al. (2003) \\
\hline & Ephemenoptera & ara $2 / 2$ & $*$ \\
\hline & Odonata & $3 / 3$ & Tanaka (2000c) \\
\hline & Orthoptera & $18 / 18$ & Tanaka $(1993,2004 b), *$ \\
\hline & Phasmatidae & $1 / 1$ & $*$ \\
\hline & $\begin{array}{l}\text { Mantophas- } \\
\text { matodea }\end{array}$ & $1 / 1$ & $*$ \\
\hline & Dictyoptera & $3 / 3$ & Tanaka (2000c) \\
\hline & Dermaptera & $1 / 1$ & Tanaka (2000c) \\
\hline & Isoptera & $2 / 2$ & Tanaka (2000c), * \\
\hline & Plecoptera & $2 / 2$ & $*$ \\
\hline & Homoptera & $3 / 3$ & Tanaka $(2000 c), *$ \\
\hline & Hemiptera & $6 / 6$ & Tanaka (2000c) \\
\hline & Neuroptera & $1 / 1$ & $*$ \\
\hline & Coleoptera & $0 / 13$ & $\begin{array}{l}\text { Tanaka (2000c), } \\
\text { Roller et al. (2003), * }\end{array}$ \\
\hline & Mecoptera & $1 / 1$ & $*$ \\
\hline & Trichoptera & $6 / 6$ & $*$ \\
\hline & Lepidoptera & $11 / 11$ & Tanaka $(1993,2000 \mathrm{c}), *$ \\
\hline & Diptera & $7 / 7$ & Tanaka (2000c), ${ }^{*}$ \\
\hline & Hymenoptera & $7 / 7$ & $\begin{array}{l}\text { Tanaka (2000c), } \\
\text { Roller et al. (2006) }\end{array}$ \\
\hline
\end{tabular}

* Tanaka (unpublished). The species tested include Araneus sp., Nephila sp. (Araneida), Armadillidium vulgare (Isopoda), Isonychia japonica, Epeorus latiforlium (Ephemeroptera), an unidentified species (Isoptera), Hemilobophasma montaguensis (Mantophasmatodea), Paratenodera angustipennis (Phasmatidae), Oyamia gibba, an unidentified sp. (Plecoptera), Atuphora stictica (Homoptera), Leptocorixa cirbetti, Physopelta cincticollis (Hemiptera), Panorpa japonica (Mecoptera), Mimela splendens, Anomala sp., Dasylepidae ishigakiensis, Hydaticus vittatus, Tenebrio obscurus (Coleoptera), Hydropsyche orientalis, Oecetis nigropunctata, Cheumatopsyche infascia, Lepidostoma orientale, Glossosoma sp., Gumago sp. (Tricoptera), Ampelophaga rubiginosa (Lepidoptera) and Tipula aino (Diptera) collected as adults at various localities.

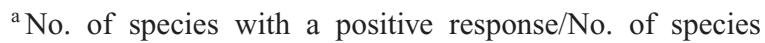
tested.

in origin. Heelwakers, belonging to a recently discovered new insect order, Mantophasmatodea, also gave a positive response (Fig. 5), although the chemical identification of the compound has not yet been performed. On the other hand, no darkcolor inducing activity was shown by two non-insect classes. In the isopod, no immunoreactivity 


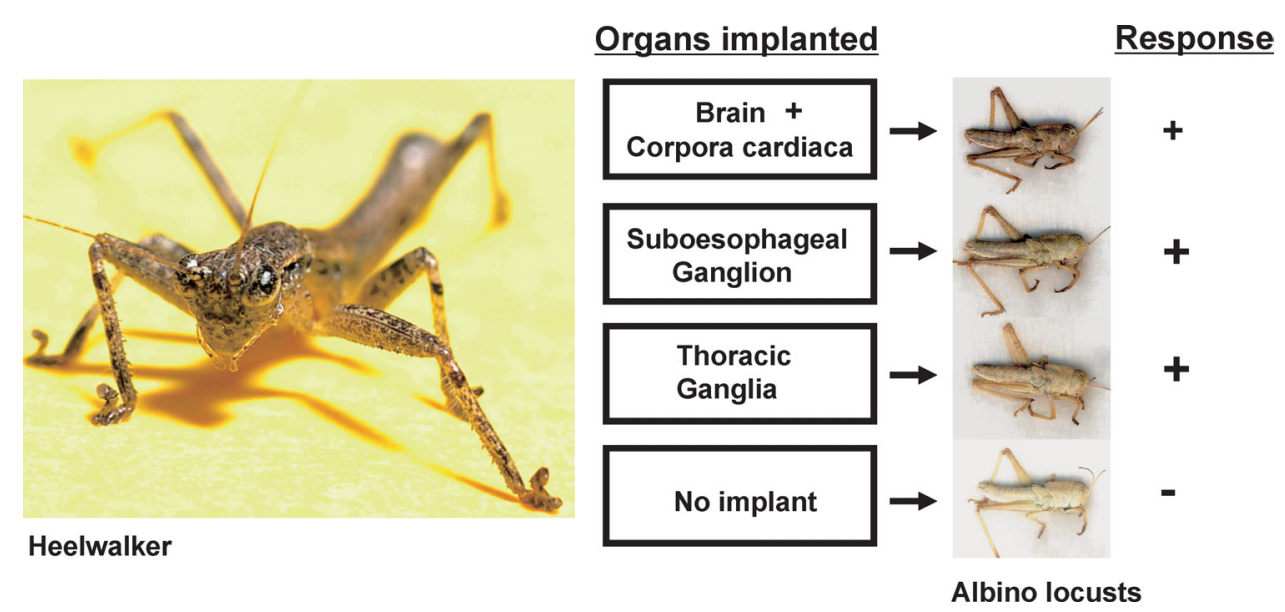

Fig. 5. Dark-color inducing activity of various organs from a heelwalker, Hemilobophasma montaguensis when implanted into albino nymphs of Locusta migratoria.

was found when tested with an antibody against Sca-corazonin (Tanaka and Kotaki, unpublished data). Among all insect orders so far examined, we have not been successful in obtaining a positive response from the Coleoptera. The same conclusion was reached by experiments with additional five species including a flour beetle, water beetles, and scarab beetles (Table 2; Tanaka, unpublished). For coleopteran species, $2-5$ brains and CC pairs were removed from each species and implanted into an albino locust, but no positive response was obtained. We confirmed the absence of corazonin in the central nervous system of a scarab beetle, Anomala cuprea by immunohistochemistry (Roller et al., 2003).

From these preliminary observations, it appears that corazonin and similar compounds are common among insects except for the Coleoptera. The presence of a particular molecule type of corazonin has been determined only for a limited number of species, but according to available evidence, Scacorazonin is found only in the Orthoptera (Veenstra, 1991; Tawfik et al., 1999), Phasmatodea (Predel et al., 1999) and Hymenoptera (Roller et al., 2006; Verleyen et al., 2006), whereas Pea-corazonin is widely distributed among insect orders including the Orthoptera (Hua et al., 2000), Dictyoptera (Veenstra, 1989; Petri et al., 1995), Diptera (Cantera et al., 1994; Veenstra, 1994) and Lepidoptera (Veenstra, 1991; Hua et al., 2000; Hansen et al., 2001; Qi-Miao et al., 2003). Recently, it was detected in the pericardial organs of a crab, Cancer borealis (Lie et al., 2003). The corazonin-like sub- stance from a honey bee (Tanaka, 2000c) is likely to constitute another molecule type (Fig. 1), because the genome of this bee does not contain the DNA sequence encoding the above two molecules (Y. Tanaka, personal communications). Isolation of corazonin-like substances in this and other species as well as identification of the functional role in those insects will provide important information about the evolution of neuropeptides (Tanaka, 2001).

\section{CONCLUDING REMARKS}

Not all albino mutants in locusts are deficient in the same factor. For example, the CC of an albino strain of $S$. gregaria contains corazonin. Implantation of extra CC taken from normal individuals is not effective in inducing darkening in this strain, but the $\mathrm{CC}$ of the latter can induce darkening in the Okinawa albino strain of L. migratoria when implanted (Schoofs et al., 2000; Yerushalmi et al., 2000). Thus, the albinism in S. gregaria is not caused by the absence of corazonin. The establishment of the Okinawa albino strain led us to identify the dark-color inducing factor in normal strains of the two locusts. We suggested earlier for this neuropeptide to be called the dark-color inducing neuropeptide (DCIN) (Tanaka and Pener, 1994a), but now we know that it has other physiological functions in locusts and other insects. Therefore, it is no longer appropriate to keep the name for this neuropeptide. In this review, 'Sca-corazonin' was used simply because it was first discovered from 
S. americana (Veenstra, 1991). The recent findings described above strongly indicate that Sca-corazonin is involved in the control of the development of some phase-related characters in locusts. Adult locusts turn yellowish when they sexually mature under crowded conditions (Pener, 1991). With the albino strain, the possible presence of a yellowcolor inducing factor has also been suggested to be present in the CC of adult L. migratoria (Hasegawa and Tanaka, 1994), although the nature of this factor is yet to be determined.

The corazonin model proposed for the body color polyphenism in the two locusts should be tested in the future. The hormonal titers are determined by the balance of release and degradation of the hormone. Determination of the corazonin titers in locusts has not been carried out in relation to the body color. The physiological activity depends not only on the hormonal titers, but also on the presence and absence of the receptors in the tissue. Therefore, it is important to obtain information about the receptor system. Recent development in molecular biology provides a unique opportunity to test the above hypothesis and the possible roles of corazonin in the development of other phase-related characters. In this sense, the isolation of the corazonin-gene in Drosophila melanogaster (Veenstra, 1994) and in Galleria mellonela (Hansen et al., 2001) is encouraging. Recent molecular studies indicate phase-related differences in expression of numerous genes in L. migratoria (Kang et al., 2005), although how these genes are involved in the control of phase polyphenism is not known.

\section{ACKNOWLEDGEMENTS}

I am deeply indebted to Dr. Y. Tamaki (former Department Head of the National Institute of Sericultural and Entomological Science) and Dr. S. Masaki (Professor Emeritus of Hirosaki University) for having inspired me to start locust research. Ms. S. Ogawa, Ms. H. Ikeda, Mr. K. Maeno and Mr. M. Kaneko assisted with rearing insects. Dr. M. Shiga (former Department Head of NISES), Dr. K. Kawasaki, Dr. T. Kotaki, Mr. M. Watanabe, Dr. D. H. Zhu and Dr. T. Okuda gave me much encouragement and valuable suggestions. Dr. K. Tojo (Sinshu University) and Dr. T. Tsutsumi (Fukushima University) sent me heelwalkers and mayflies, Mr. Y. Tomioka (Ikari Co.) sent me flour beetles, Mr. M. Suenaga (NIAS) organized light-trap trips to collect many insects for corazonin assays, and Mr. N. Kawase identified caddish flies. To all, I am most grateful. Special thanks are due to Ms. N. Kemmochi for her long-term assistance and dedication to this project. The grass used was raised by the Field Management Section of NIAS at Ohwashi. Figures 2 and 4 are reproduced with permission from Elsevier Sciences Press. This study was partially supported by a grant (17580048) from Kakenhi (Japan). The two anonymous referees and an editor improved the manuscript.

\section{REFERENCES}

Applebaum, S. W., E. Avisar and Y. Heifetz (1997) Juvenile hormone and locust phase. Arch. Insect Biochem. Physiol. 35: 375-391.

Applebaum, S. W. and Y. Heifetz (1999) Density-dependent physiological phase in insects. Annu. Rev. Entomol. 44: 317-341.

Baggerman, G., E. Clynen, R. Mazibur, D. Veelaert, M. Breuer, A. De Loof, S. Tanaka and L. Schoofs (2001) Mass spectrometric evidence for the deficiency in the dark-color-inducing hormone, [His $\left.{ }^{7}\right]$-corazonin in an albino strain of Locusta migratoria as well as for its presence in solitary Schistocerca gregaria. Arch. Insect Biochem. Physiol. 47: 150-160.

Breuer, M., B. Hoste and A. De Loof (2003) The endocrine control of phase transition: some new aspects. Physiol. Entomol. 28: 3-10.

Byers, J. A. (1991) Pheromones and chemical ecology of locusts. Biol. Rev. 66: 347-378.

Cantera, R., J. A. Veenstra, D. R. Nassel (1994) Postembryonic development of corazonin-containing neurons and neurosecretory cells in the blowfly, Phormia terraenovae. J. Comp. Neurol. 350: 559-572.

Cassier, P. (1964) Effects immediats et transmis des implantations de corps allates sur la fecondité et la descendance des femelles de Locusta migratoria migratorioides ( $\mathrm{R}$. \& F.), phase gregarire (Insecte, Orthopteroide). C. $R$. Hebd. Seanc. Acad. Sci. 259: 2706-2708.

Cassier, P. (1965) Determinisme endocrine de quelques caractéristiques phasaires chez Locusta migratoria migratorioides (R. \& F.) (Insecte orthopteroide, Acrididae). Insectes Soc. 12: 71-79.

Chapman, R. F. (1976) A Biology of Locusts. The Institute of Biology's Studies in Biology. No. 71. Camelot Press, Southhampton. 67 pp.

Dale, J. F. and S. S. Tobe (1990) The endocrine basis of locust phase polymorphism. In Biology of Grasshoppers (R. F. Chapman and A. Joern eds.). John Wiley and Sons, New York, pp. 393-414.

Dingle, H. (1996) Migration. Oxford University Press, Oxford. $469 \mathrm{pp}$

Dirsh, V. M. (1951) A new biometrical phase character in locusts. Nature 167: 281-282.

Dirsh, V. M. (1953) Morphometrical studies on phases of the desert locust. Anti-Locust Bull. 16: 1-34.

Ellis, P. E. (1953) Social aggregation and gregarious behaviour in hoppers of Locusta migratoria migratorioides (R. and F.). Behaviour 5: 225-260.

Ellis, P. E. (1959) Some factors influencing phase characters in the nymphs of the locust, Locusta migratoria migratorioides (R. \& F.). Insectes Soc. 6: 21-39.

Ellis, P. E. (1962) The behaviour of locusts in relation to phases and species. Colloq. Int. Cent. Nat. Rech. Sci. 114: 123-143. 
Ellis, P. E. (1963) The influence of some environmental factors on learning and aggregating in locust hoppers. Anim. Behav. 11: 142-151.

Ellis, P. E. and D. B. Carlisle (1961) The prothoracic gland and colour change. Nature 190: 368-369.

Faure, J. C. (1932) The phases of locusts in South Africa. Bull. Entomol. Res. 23: 293-405.

Ferenz, H.-J. and K. Seidelmann (2003) Pheromeones in relation to aggregation and reproduction in desert locusts. Physiol. Entomol. 28: 11-28.

Fuzeau-Braesch, S. (1985) Color changes. In Comprehensive Insect Physiology Biochemistry and Pharmacology. Vol. 11 (G. A. Kerkut and L. I. Gilbert eds.). Pergamon Press, Oxford, pp. 549-589.

Girardie, A. and M. Cazel (1965) Role de la pars intercerebralis et des corpora cardiaca sur Laemelanization chez Locusta migratoria (L.). C. R. Hebd. Seanc. Acad. Sci. Paris 261: 4525-4527.

Greenwood, M. and R. F. Chapman (1984) Differences in number of sensilla on the antennae of solitarious and gregarious Locusta migratoria L. (Orthoptera: Acrididae). Int. J. Insect Morphol. Embryol. 13: 295-301.

Hägele, F. H., V. Oag, A. Bouaïchi, A. R. McCarffery and S. J. Simpson (2000) The role of female accessory glands in maternal inheritance of phase in the desert locust Schistocerca gregaria. J. Insect Physiol. 46: 275-280.

Halls, K. M. (2004) Albino Animals. Darby Creek Publishing, Plain City, USA. 74 pp.

Hansen, I. A., F. Sehnal, S. R. Meyer and K. Scheller (2001) Corazonin gene expression in the waxmoth, Galleria mellonella. Insect Mol. Biol. 19: 341-346.

Harrison, R. G. (1980) Dispersal polymorphism in insects. Annu. Rev. Ecol. Syst. 11: 95-118.

Hasegawa, E. and S. Tanaka (1994) Genetic control of albinism and the role of juvenile hormone in pigmentation in Locusta migratoria (Orthoptera: Acrididae). Jpn. J. Entomol. 62: 315-324.

Hassanali, A., P. B. N. Njago and M. O. Bashir (2005) Chemical ecology of locusts and related acridids. Аnпи. Rev. Entomol. 50: 223-245.

Heifetz, Y., S. W. Applebaum and G. B. Popov (1994) Phase characteristics of the Israeli population of the migratory locust, Locusta migratoria (L.) (Orthoptera: Acrididae). J. Orthop. Res. 2: 15-20.

Hoste, B., S. J. Simpson, A. De Loof and M. Breuer (2003) Behavioural differences in Locusta migratoria associated with albinism and their relation to $\left[\mathrm{His}^{7}\right]$ corazonin. Physiol. Entomol. 28: 32-38.

Hoste, B., S. J. Simpson, S. Tanaka, A. De Loof and M. Breuer (2002a) A comparison of phase-related shifts in behavior and morphometrics of an albino strain, deficient in [His $\left.{ }^{7}\right]$-corazonin and a normally colored Locustra migratoria strain. J. Insect Physiol. 48: 791-801.

Hoste, B., S. J. Simpson, S. Tanaka, D. H. Zhu, A. De Loof and M. Breuer (2002b) Effects of $\left[\mathrm{His}^{7}\right]$-corazonin on the phase state of isolated-reared (solitarious) desert locusts, Schistocerca gregaria. J. Insect Physiol. 48: 891990.

Hua, Y.-J., J. Ishibashi, H. Saito, A. I. Tawfik, M. Sakakibara,
Y. Tanaka, R. Derua, E. Waelkens, G. Baggerman, A. De Loof, L. Schoofs and S. Tanaka (2000) Identification of $\left[\mathrm{Arg}^{7}\right]$ corazonin in the silkworm, Bombyx mori and the cricket, Gryllus bimaculatus, as a factor inducing dark color in an albino strain of the locust, Locusta migratoria. J. Insect Physiol. 46: 853-859.

Hunter-Jones, P. (1957) An albino strain of desert locust. Nature 180: 237.

Hunter-Jones, P. (1958) Laboratory studies on the inheritance of phase characters in locusts. Anti-Locust Bull. 29: $1-32$

Husain, M. A. and T. Ahmad (1936) Studies on Schistocerca gregaria Forsk. VI. Influence of temperature on the intensity and extent of black pattern in the desert locust hoppers bred crowded. Indian J. Agric. Sci. 6: 624-664.

Ignell, R., F. Couilland and S. Anton (2001) Juvenile-hormone-mediated plasticity of aggregation behaviour and olfactory processing in adult desert locusts. J. Exp. Biol. 204: 249-259.

Islam, M. S. (1995) Endocrine manipulations in crowdreared desert locust Schistocerca gregaria. I. Effects of juvenile hormone analogues on morphology and reproductive parameters. Pakistan J. Zool. 27: 301-310.

Islam, M. S., P. Roessingh, S. J. Simpson and A. R. McCaffery (1994a) Parental effects on the behaviour and colouration of nymphs of the desert locust, Schistocerca gregaria. J. Insect Physiol. 40: 173-181.

Islam, M. S., P. Roessingh, S. J. Simpson and A. R. McCaffery (1994b) Effects of population density experienced by parents during mating and oviposition on the phase of hatchling desert locusts, Schistocerca gregaria. Proc. $R$. Soc. Lond. B 257: 93-98.

Joly, P. and L. Joly (1954) Resultats de greffes de corpora allata chez Locusta migratoria L. Ann. Sci. Nat. (Zool.) Ser. 11. 15: 331-345.

Kang, L., X. Y. Chen, Y. Zhou, B. Liu, W. Zheng, R. Li, J. Wang and J. Yu (2005) The analysis of large-scale gene expression correlated to the phase changes of the migratory locust. Proc. Natl. Acad. Sci. USA 101: 1761117615 .

Lester, B. L., C. Grach, M. P. Pener and S. J. Simpson (2005) Stimuli inducing gregarious colouration and behaviour in nymphs of Schistocerca gregaria. J. Insect Physiol. 51: 737-747.

Li, L., W. P. Kelley, C. P. Billimoria, A. E. Christie, S. R. Pulver, J. V. Sweedler and E. Mander (2003) Mass spectrometric investigation of the neuropeptide complement and release in the pericardial organs of the crab, Cancer borealis. J. Neurochem. 87: 642-656.

Loher, W. (1990) Pheromones and phase transformation in locusts. In Biology of Grasshoppers (R. F. Chapman and A. Joern eds.). John Wiley and Sons, New York, pp. $337-355$

Maeno, K., T. Gotoh and S. Tanaka (2004) Phase-related morphological changes induced by $\left[\mathrm{His}^{7}\right]$-corazonin in two species of locusts, Schistocerca gregaria and Locusta migratoria (Orthoptera: Acrididae). Bull. Entomol. Res. 94: 349-357.

Maeno, K. and S. Tanaka (2004) Hormonal control of phase- 
related changes in the number of antennal sensilla in the desert locust, Schistocerca gregaria: possible involvement of [His $\left.{ }^{7}\right]$-corazonin. J. Insect Physiol. 50: 855865.

Malual, A. G., A. Hassanali, B. Torto, Y. O. H. Assad and O. G. N. Njagi (2001) The nature of the gregarizing signal responsible for maternal transfer of phase to the offspring in the desert locust. J. Chem. Ecol. 27: 1423-1435.

McCaffery, A. R., S. J. Simpson, M. S. Islam and P. Roessingh (1998) A gregarizing factor present in the egg pod foam of the desert locust, Schistocerca gregaria. J. Exp. Biol. 201: 347-363.

Mordue (Luntz), A. J. (1977) Some effects of amputation of the antennae on pigmentation, growth and development in the locust, Schistocerca gregaria. Physiol. Entomol. 2: 293-300.

Muszynska-Pytel, M. and B. Cymborowski (1978) The role of serotonin in regulation of the circadian rhythms of locomotor activity in the cricket (Acheta domesticus L.). I. Circadian variations in serotonin concentration in the brain and hemolymph. Comp. Biochem. Physiol. C 59: 13-15.

Nickerson, B. (1956) Pigmentation of hoppers of the desert locust (Schistocerca gregaria (Forskal) in relation to phase coloration. Anti-Locust Bull. 24: 1-34.

Nolte, D. J. (1967) Phase transformation and chiasma formation in locusts. Chromosoma 21: 123-139.

Nolte, D. J. (1968) The chiasma-inducing pheromone of locusts. Chromosoma 23: 346-358.

Ochieng, S. A., E. Hallberg and B. S. Hansson (1998) Fine structure and distribution of antennal sensilla of the desert locust, Schistocerca gregaria (Orthoptera: Acrididae). Cell Tissue Res. 291: 525-536.

Pener, M. P. (1965) Comparative studies on oxygen consumption in the albino and normal strains of Schistocerca gregaria bred under crowded and isolated conditions. In Proc. XIIth Int. Cong. Entomol. (London, 1964), pp. 222223.

Pener, M. P. (1985) Hormonal effects on flight and migration. In Comprehensive Insect Physiology Biochemistry and Pharmacology. Vol. 8 (G. A. Kerkut and L. I. Gilbert eds.). Pergamon Press, Oxford, pp. 491-550.

Pener, M. P. (1991) Locust phase polymorphism and its endocrine relations. Adv. Insect Physiol. 23: 1-79.

Pener, M. P., A. Ayali and E. Ben-Ami (1992) Juvenile hormone is not a major factor in locust phase changes. In Insect Juvenile Hormone Research (B. Mauchamp, F. Couiland and J. C. Baehr eds.). Institut National de la Recherche Agronomique, Paris, pp. 125-134.

Pener, M. P. and Y. Yerushalmi (1998) The physiology of locust phase polymorphism, an update. J. Insect Physiol. 44: 365-377.

Petri, B., M. Stengl, S. Wurden and U. Homberg (1995) Immunocytochemical characterization of the accessory medulla in the cockroach Leucophaea maderae. Cell Tissue Res. 282: 3-19.

Predel, P., R. Lellner and G. Gade (1999) Myotropic neuropeptides from the retrocerebral complex of the stick insect, Carausius morosus (Phasmatodea: Lonchodidae).
Eur. J. Entomol. 96: 275-278.

Qi-Miao, S., S. Tanaka and M. Takeda (2003) Immunohistochemical localization of clock proteins (DBT and PER), and $\left[\mathrm{His}^{7}\right]$ - and $\left[\mathrm{Arg}^{7}\right]$-corazonins in the cerebral ganglia of Bombyx mori: Are corazonins downstream regulators of circadian clocks? Eur. J. Entomol. 1000: 283-286.

Rogers, S. M., T. Matheson, K. Sasaki, K. Kendrick, S. J. Simpson and M. Burrows (2004) Substantial changes in central nervous system neurotransmitters and neuromodulators accompany phase change in locust. J. Exp. Biol. 207: 3603-3617.

Roller, L., S. Tanaka, K. Kimura, H. Satake and Y. Tanaka (2006) Molecular cloning of $\left[\mathrm{Thr}^{4}, \mathrm{His}^{7}\right]$-corazonin (Apime-corazonin) and its distribution in the central nervous system of the honey bee Apis mellifera (Hymenoptera: Apidae). Appl. Entomol. Zool. 41: 331-338.

Roller, L., Y. Tanaka and S. Tanaka (2003) Corazonin and corazonin-like substances in the central nervous system of pterygote and apterygote insects. Cell Tissue Res. 312: 393-406.

Roussel, J. P. and J. M. Perron (1974) Action de substances mimetiques de l'hormone juvenile sur Schistocerca gregaria Forsk. Ach. Zool. Exp. Gen. 115: 251-262.

Schoofs, L., G. Baggerman, D. Veelaert, M. Breuer, S. Tanaka and A. De Loof (2000) The pigmentotropic hormone [His $\left.{ }^{7}\right]$-corazonin, absent in a Locusta migratoria albino strain, occurs in an albino strain of Schistocerca gregaria. Mol. Cell. Endocrinol. 168: 101-109.

Schoofs, L., E. Clynen, A. Cerstiaens, G. Baggerman, Z. Wei, T. Vercammen, R. Nachman, A. De Loof and S. Tanaka (2001) Newly discovered functions for some myotropic neuropeptides in locusts. Peptides 22: 219-227.

Simpson, S. J., E. Despland, B. Hagele and T. Dodgson (2001) Gregarious behaviour in desert locusts is evoked by touching their back legs. Proc. Natl. Acad. Sci. USA 98: 3895-3897.

Staal, G. B. (1961) Studies on the Physiology of Phase Induction in Locusta migratoria migratorioides $R$. \& F. H. Veenman \& Zonen N. V., Wageningen, The Netherlands. $125 \mathrm{pp}$.

Tanaka, S. (1993) Hormonal deficiency causing albinism in Locusta migratoria. Zool. Sci.10: 467-471.

Tanaka, S. (1996) A cricket (Gryllus bimaculatus) neuropeptide induces dark colour in the locust, Locusta migratoria. J. Insect Physiol. 42: 287-294.

Tanaka, S. (2000a) The role of $\left[\mathrm{His}^{7}\right]$-corazonin in the control of body-color polymorphism in the migratory locust, Locusta migratoria (Orthoptera: Acrididae). J. Insect Physiol. 46: 1169-1176.

Tanaka, S. (2000b) Hormonal control of body-color polymorphism in Locusta migratoria: interaction between [His $\left.{ }^{7}\right]$-corazonin and juvenile hormone. J. Insect Physiol. 46: 1535-1544.

Tanaka, S. (2000c) Induction of darkening by corazonins in several species of Orthoptera and their possible presence in ten insect orders. Appl. Entomol. Zool. 35: 509-517.

Tanaka, S. (2001) Endocrine mechanisms controlling bodycolor polymorphism in locusts. Arch. Insect Biochem. Physiol. 47: 139-149. 
Tanaka, S. (2003) Effects of temperature and [His $\left.{ }^{7}\right]$-corazonin on the body darkening in Locusta migratoria. Physiol. Entomol. 28: 290-297.

Tanaka, S. (2004a) Environmental control of body-color polyphenism in the American grasshopper, Schistocerca americana. Ann. Entomol. Soc. Am. 97: 293-301.

Tanaka, S. (2004b) Hormonal control of body-color polyphenism in the American grasshopper, Schistocerca americana: a physiological function of $\left[\mathrm{His}^{7}\right]$-corazonin. Ann. Entomol. Soc. Am. 97: 302-309.

Tanaka, S. (2005) Hormonal control of phase polyphenism in locusts. Formosan Entomol. 25: 131-143.

Tanaka, S. and M. P. Pener (1994a) A neuropeptide controlling the dark pigmentation in color polymorphism of the migratory locust, Locusta migratoria. J. Insect Physiol. 40: 997-1005.

Tanaka, S. and M. P. Pener (1994b) Induction of dark color by a neurohormone in Locusta migratoria. In Proc. 1st International Conference on Insects: Chemical, Physiological and Environmental Aspects (D. Konopinska ed.). University of Wroclaw, Poland, pp. 141-145.

Tanaka, S. and N. Takeda (1996) Biogenic monoamines in the brain and the corpus cardiacum between albino and normal strains of the migratory locust, Locusta migratoria. Comp. Biochem. Physiol. 117C: 221-227.

Tanaka, S. and S. Yagi (1997) Evidence for the involvement of a neuropeptide in the control of body color in the desert locust, Schistocerca gregaria. Jpn. J. Entomol. 65: 447-457.

Tanaka, S. and D.-H. Zhu (2003) Phase-related differences in mating strategy of a locust (Orthoptera: Acrididae). Ann. Entomol. Soc. Am. 96: 498-502.

Tanaka, S. and D.-H. Zhu (2005) Outbreaks of the migratory locust Locusta migratoria (Orthoptera: Acrididae) and control in China. Appl. Entomol. Zool. 40: 257-263.

Tanaka, S., D.-H. Zhu, B. Hoste and M. Breuer (2002) The dark-color inducing neuropeptide, $\left[\mathrm{His}^{7}\right]$-corazonin, causes a shift in morphometric characteristics towards the gregarious phase in isolated-reared (solitarious) Locusta migratoria. J. Insect Physiol. 48: 1065-1074.

Tanaka, Y., Y.-J. Hua, L. Roller and S. Tanaka (2002) Corazonin reduces the spinning rate in the silkworm, Bombyx mori. J. Insect Physiol. 48: 707-714.

Tanaka, Y., J. Ishibashi and S. Tanaka (2003) Comparison of structure-activity relations of corazonin using two different bioassay systems. Peptides 24: 837-844.

Tawfik, I. M., S. Tanaka, A. De Loof, L. Schoofs, G. Baggerman, E. Waelkens, R. Derua, Y. Milner, Y. Yerushalmi and M. P. Pener (1999) Identification of the gregarization-associated dark-pigmentropin in locusts through an albino mutant. Proc. Natl. Acad. Sci. USA 96: 70837087.

Torto, B., P. G. N. Njagi, A. Hassanali and H. Amiani (1996) Aggregation pheromone system of nymphal gregarious desert locust Schistocerca gregaria (Foskål). J. Chem. Ecol. 22: 2273-2281.

Torto, B., D. Obeng-Ofori, P. G. N. Njagi, A.v Hassanali and H. Amiani (1994) Aggregation pheromone system of adult gregarious desert locust Schistocerca gregaria
(Foskål). J. Chem. Ecol. 20: 1749-1762.

Uvarov, B. P. (1921) A revision of the genus Locusta, L. (=Pachytylus, Fieb.), with a new theory as to the periodicity and migrations of locusts. Bull. Entomol. Res. 12: 135-163.

Uvarov, B. P. (1923) Notes on locusts of economic importance, with some new data on the periodicity of locust invasion. Bull. Entomol. Res. 14: 31-39.

Uvarov, B. P. (1966) Grasshoppers and Locusts. Vol. 1. Cambridge University Press, Cambridge. 481 pp.

Uvarov, B. P. (1977) Grasshoppers and Locusts. Vol. 2. Centre for Overseas Pest Research, London. 475 pp.

Veenstra, J. A. (1989) Isolation and structure of corazonin, a cardioactive peptide from the American cockroach. FEBS Lett. 250: 231-234.

Veenstra, J. A. (1991) Presence of corazonin in three insect species, and isolation and identification of $\left[\mathrm{His}^{7}\right]$ corazonin from Schistocerca americana. Peptides 12: 12851298.

Veenstra, J. A. (1994) Isolation and structure of the Drosophila corazonin gene. Biochem. Biophys. Res. Commun. 204: 292-296.

Verdier, M. (1965) Mutation albinos de Locusta migratoria. I. Origine et description (C.S.). Bull. Soc. Zool. Fr. 90: 493-501.

Verleyen, P., G. Baggerman, I. Mertens, T. Vandersmissen, J. Huybrechts, A. V. Lommel, A. De Loof and L. Schoofs (2006) Cloning and characterization of a third isoform of corazonin in the honey bee Apis mellifera. Peptides 27: 493-499.

Yamamoto-Kihara, M., T. Hata, M. Breuer and S. Tanaka (2004) Effect of $\left[\mathrm{His}^{7}\right]$-corazonin on the number of antennal sensilla in Locusta migratoria. Physiol. Entomol. 29: 73-77.

Yerushalmi, Y., K. Bhargava, C. Gilon and M. P. Pener (2002) Structure-activity relations of the dark-colour inducing neurohormone of locusts. Insect Biochem. Mol. Biol. 32: 909-917.

Yerushalmi, Y., L. Livshits and M. P. Pener (2000) The darkcolor-inducing neurohormone of locusts in relation to an albino mutant of Schistocerca gregaria. Physiol. Entomol. 25: 127-132.

Yerushalmi, Y. and M. P. Pener (2001) The response of a homochrome grasshopper, Oedipoda miniata, to the darkcolour inducing neurohormone (DCIN) of locust. J. Insect Physiol. 47: 593-597.

Yerushalmi, Y., E. Tauber and M. P. Pener (2001) Phase polymorphism in Locusta migratoria: the relative effects of geographic strains and albinism on morphometrics. Physiol. Entomol. 26: 95-105.

Zhao, Z. and A. J. Zera (2004) The hemolymph JH titer exhibits a large-amplitude, morph-dependent, diurnal cycle in the wing-polymorphic cricket, Gryllus firmus. J. Insect Physiol. 50: 93-102.

Zhu, D.-H. and S. Tanaka (2002) Prolonged precopulatory mounting increases the length of copulation and sperm precedence in Locusta migratoria (Orthoptera: Acrididae). Ann. Entomol. Soc. Am. 95: 370-373. 